I Katon W, Vitaliano PP, Russo J, Jones M, Anderson K. Panic disorder: spectrum of severity and somatization. F Nerv Ment Dis 1987;175:12-9.

2 Klein DF. Delineation of two drug-response anxiety syndromes. Psychopharmacologia 1964;5:397 408.

Klein DF. Importance of psychiatric diagnosis in prediction of clinical drug effects. Arch Gen Psychiatry 1967;16:118-26.

4 American Psychiatric Association. Diagnostic and statistical manual for mental disorders. 3rd revision revised. Washington: APA, 1987

World Health Organisation. International classification of diseases, draft for 10th revision. Geneva WHO, 1987.

6 Klein DF, Fink M. Psychiatric reaction patterns to imipramine. Am J Psychiatry 1962;119: $+32-8$

Sheehan DV, Ballenger J, Jacobsen G. Treatment of endogenous anxiety with phobic, hysterical, and hypochondriacal symptoms. Arch Gen Psychiatry 1980;37:51-9.

Zitrin CM, Klein DF, Woerner MG, Ross DC. Treatment of phobias. I. Comparison of imipramine hydrochloride and placebo. Arch Gen Psychiatry 1983;40:125-38.

Liebowitz MR. Imipramine in the treatment of panic disorder and its complications. Psychiatr Clin North Am 1985;8:37-47.

$10 \mathrm{~L}$ diard RB, Ballenger JC. Antidepressants in panic disorder and agoraphobia. I Affective Disord 1987; 13:153-68

11 Tyrer P. Classification of anxiety disorders: a critique of DSM-111. I Affective Disord 1986;11: 99-104.

12 Chouinard G, Annable L, Fontaine R, Solyom L. Alprazolam in the treatment of generalised anxiety and panic disorders: a double-blind placebo-controlled study. Psychopharmacolog 1982;77:229-33.
13 Klerman GL. Overview of the cross-national collaborative panic study. Arch Gen Psychiatry 1988; $45: 407-12$

14 Ballenger JC, Burrows GD, DuPont RL, et al. Alprazolam in panic disorder and agoraphobia: results from a multicenter trial. I. Efficacy in short-term treatment. Arch Gen Psychiatry

15 Noyes R Jr, Pecknold JC, Rifkin A, et al. Alprazolam in panic disorder: results from a multicenter trial. II. Patient acceptance, side effects, and safety. Arch Gen Psychiatry 1988;45:423-8.

6 Pecknold JC, Swinson RP, Kuch K, Lewis CP. Agoraphobia in panic disorder and agoraphobia: results from a multicenter trial. III. Discontinuation effects. Arch Gen Psychiary 1988;45:429-36. Fontaine R, Chouinard G, Annable L. Rebound anxiety in anxious patients after abrupt withdrawal of benzodiazepine treatment. Am $\mathcal{F}$ Psychiatry 1984;141:848-52.

18 Murphy SM, Owen RT, Tyrer P. Withdrawal symptoms after six weeks, treatment with diazepam. Lancet 1984;ii: 1389.

19 Tyrer P. The role of bodily feelings in anxiety. London: Oxford University Press, 1976.

20 Shehi M, Patterson W. Treatment of panic with alprazolam and propranolol. Am 7 Psychiatry 1984;141:900-1.

21 Clark DM. A cognitive approach to panic. Behav Res Ther 1986;24:461-70.

22 Clark DM, Salkovskis PN, Chalkley AJ. Respiratory control as a treatment of panic attack. J Behav Ther Exp Psychiatry 1985;16:23-30.

23 Gelder MG. Panic attacks: new approaches to an old problem. Br F Psychiatry 1986;149:346-52.

24 Barlow DH, Cerny J. Psychological treatment of panic. New York: Guilford, 1988.

25 Marks I. Behavioural psychotherapy in general psychiatry: helping patients to help themselves. Br f Psychiatry 1987; 150:593-7.

26 Tyrer P, Seivewright N, Murphy S, et al. The Nottingham study of neurotic disorder: comparison of drug and psychological treatments. Lancet 1988;ii:235-40.

\title{
The rise in private hospital care
}

\author{
Unpredictable implications
}

Data on the treatment of patients by the private sector in Britain are not routinely available. Knowledge about this activity comes from research surveys, and two of these, covering England and Wales in 1981 and 1986, by Nicholl et $a l$, are published today (p 239 and p 243). Excluding psychiatric and maternity care, the authors estimate that the private sector accounted for about $7 \%$ of all inpatient admissions in 1986 and that admissions in the private sector had increased by $57 \%$ from 1981 . Termination of pregnancy was the single commonest reason for admission, accounting for $28 \%$ of admissions in 1981 and $19 \%$ in 1986 . The case mix was otherwise similar for the two years and consisted mainly of elective operations.

Most admissions were for conditions for which there are waiting lists in the NHS. Considering all elective operations, the authors estimate that $17 \%$ of inpatients and $11 \%$ of day cases in England and Wales were treated in the private sector in 1986; a fifth of all inguinal hernia repairs and over a quarter of all hip replacements were undertaken privately. Compared with the NHS the private sector treated proportionately fewer children and patients aged 65 years and over. There was wide geographical variation in the proportion of elective surgical conditions treated in the private sector - from $6 \%$ in the Northern region to a third in two of the Thames regions. Thus, although the private sector has grown considerably, it still provides treatment for only a limited range of conditions and a limited group of people in limited areas.

Could the independent sector increase substantially its contribution to health care in Britain? Nicholl et al question the scope for expansion into expensive high technology medicine, and it seems unlikely that the private sector would be able or willing to take on the comprehensive, open ended commitments of the NHS. None the less, with determination, financing, and incentive the private sector could, no doubt, expand its range of activities and grow further.

One constraint is the availability of professional staff. Important factors include past and present planning of medical school intake and medical career structures ${ }^{1-3}$ and the substantial reduction in the next few years in school leavers. ${ }^{+}$ Further short term expansion of the private sector will probably be possible only if professional staff can be attracted away from the NHS. In the longer term, national investment in training health professionals could be increased, and the option exists of recruiting labour from overseas markets. An increase in private sector activity might diminish the monopoly power of the NHS as an employee, and competitive pressure might result in an increase in salaries and improvements in working hours in health care.

It is important that private care is available for those services that are not available through, or not provided on a suitable time scale by, the NHS. What are the advantages and disadvantages of private sector care? Reports on the subject are burgeoning, ${ }^{5-11}$ but much remains speculative. An increase in private sector care would probably erode the principle of providing health care according to need rather than ability to pay. This apart, much would depend on three key interrelated issues. The first is whether private provision will continue to be seen by the government as a means of adding to rather than substituting for NHS funding. Expenditure on health care in England and Wales is recognised to be low relative to that in other industrialised countries. ${ }^{12}$ An increase in private expenditure, in addition to sustained and expanded funding for the NHS, might increase total expenditure on health care by reducing the power of government to cash limit it. The second issue is whether an increase in private care would by default adversely affect the NHS - for example, by depleting it of skilled staff or making doctors more difficult to contact for NHS emergencies. The third issue is whether the NHS would be expected and enabled to compete with the private sector with regard to those issues that influence people most in seeking private care-short waiting times, convenience, choice, privacy, comforts, and amenities - or whether the NHS would eventually become a second class service.

The question of whether economies in health care provision without sacrifice of quality might come from an expanded private sector is difficult. Detailed information on costing in the NHS and on comparisons of cost effectiveness between the private and public sectors is lacking. There are also notorious difficulties in measuring health care inputs and outcomes in ways that allow conclusions about different sectors giving value for money. Few doubt, however, the BMA's conclusion that the NHS "represents outstandingly good value." Nicholl et al show that when individual conditions were compared day case care was, if anything, less 
likely in the private than the public sector; lengths of stay in the two sectors were not appreciably different; and rates of bed occupancy were much lower in the private than the public sector. There is also a concern that fee for service care may increase discretionary and unnecessary clinical intervention. ${ }^{5}$ None the less, an element of competition between the public and private sectors might highlight areas in which further efficiencies might be made.

An expansion of private care has implications for resource allocation and planning within the NHS. Nicholl et al suggest that resource allocation within the NHS should take account of geographical variation in the provision of private care. This may have some merit in terms of equity. It would, however, establish the practice of private funding as a substitute for NHS funding, and it might lead to a downward spiral of standards in the NHS - reduced NHS funding leading to lower standards of care, leading to more people seeking private care, leading to further reductions in NHS funding, and so on.

Health service planners will need to decide whether local services should be planned for the total care required for their population or whether plans should include estimates of care that may be given in the private sector. This would require more information than that currently available on the private sector. The difference between the approaches in the volume of services planned may be considerable. More generally, we must formulate our views on the loss of part of the NHS "market" to the private sector. Is the loss a welcome relief for a hard pressed service or should the NHS try to recapture it?

MICHAEL GOLDACRE

Lecturer in Community Medicine,

University of Oxford,

Department of Community Medicine and General Practice,

Radcliffe Infirmary, Oxford OX2 6HE

Department of Health and Social Security. Medical manpower: the next twenty years. London: HMSO, 1978.

2 Parkhouse J. Medical manpower in Britain. Edinburgh: Churchill Livingstone, 1979:1-49. Department of Health and Social Security. Hospital medical staffing: achiering a bulance. London: DHSS, 1986

4 Conroy M, Stidston M. 2001: The black hole. An examination of labour market trends in relation to the National Health Service. Oxford: South West Thames and Oxford Regional Health Authorities, 1988

5 McLachlan G, Maynard A, eds. The public/private mix for health: the relevance and effects of change. London: Nuffield Provincial Hospitals Trust, 1982.

6 Peet J. Healthy competition: how to improve the NHS. London: Centre for Policy Studies, 1987.

7 Letwin O, Redwood J. Britain's biggest enterprise: ideas for radical reform of the National Health Service. London: Centre for Policy Studies, 1988.

8 Willetts D, Goldsmith M. A mixed economy for health care: more spending, same caxes. London: Centre for Policy-Studies, 1988

Cook R. Life begins at 40: in defence of the National Health Service. London: Fabian Society, 1988. Cook R. Life begins at
(Fabian Tract 529. .

10 National Association of Health Authorities. The nation's health: a way forward. Birmingham: NAHA, 1988.

11 British Medical Association. Evidence to the government internal review of the National Health Service. Br Med f 1988;296:1411-8.

12 Office of Health Economics. Compendium of health statistics. 6th ed. Part 2. London: OHE, 1987:7-11.

\section{Control of hospital infection}

\section{Enhancing present arrangements}

Patients in hospital are particularly prone to infection, which threatens the success of their treatment and even their lives. In 1979 almost a fifth of the 18186 patients surveyed in 43 British hospitals had infections, half of which were acquired in hospital. ${ }^{\prime}$ The estimated yearly cost for 1986 in England was $£ 111 \mathrm{~m}$, or a loss of 950000 bed days.

Over 10 years ago it was confirmed in the United States that surveillance, control methods, and an infection control team reduce infection rates in hospitals. ${ }^{2}$ Although most hospital acquired infection is non-epidemic, recent poorly controlled outbreaks - such as that caused by salmonella at Wakefield ${ }^{3}-$ have focused the British Department of Health's attention on the arrangements for curtailing hospital infection. Thus a hospital infection working group, chaired by Professor Mary Cooke, has recently published its clear and sensible report Hospital Infection Control-Guidance on the Control of Infection in Hospitals. ${ }^{+}$The government now wants health authorities to draw on the Cooke report and ensure that they have clear management arrangements for controlling hospital infection. Existing arrangements, despite their success in most British hospitals ${ }^{56}$ received scant mention in the chief medical officer's 1988 report Public Health in England.

The Cooke report is unambiguous that it is the district general manager, advised by the district's hospital infection control committee, who is responsible to the health authority for setting up, maintaining, and funding the arrangements for infection control in districts, units, and hospitals: "the issues of hospital infection are sufficiently clear to require the district hospital infection control committee to report directly through the district general manager to the district health authority." This committee, the report says, should include the infection control doctor (presently known as the control of infection officer); the medical microbiologist if the infection control doctor is not one; the infection control nurse; a surgeon; a physician representing the senior medical staff; a representative of the chief nursing adviser; the occupational health physician; the district medical officer; the medical officer of environmental health; the general manager; and, when he or she exists, the infectious diseases physician. Others may be co-opted.

It is the skill and experience of the infection control doctor that are crucial to controlling hospital infection. He or she is directly accountable to the unit manager and the district general manager, is responsible for the infection control nurse, and leads the infection control team (infection control doctor, infection control nurse, and the district general manager or a representative). The team conducts surveillance, initiates the response to outbreaks, and formulates and implements the policies approved by the infection control committee that have the approval and authority of the district general manager. The infection control team provides day to day monitoring and advice and implementation of policies, including isolation of patients, use of antimicrobials, infection hazards, disinfection, sterilisation, immunisation, staff education, and resource allocation. The chief medical officer acknowledges the "invaluable contribution of microbiologists to hospital infection control," and the Cooke report is clear that the infection control doctor should be a consultant with training, skill, and experience in all aspects of infection control and should have ready access to laboratory facilities. This person is likely to be the local medical microbiologist. Indeed, a survey of the Hospital Infection Society in 1986 showed that $98 \%$ of all health authorities in England and Wales already have control of infection officers; four fifths were consultant medical microbiologists who had received higher training in hospital infection control. ${ }^{8}$ 